

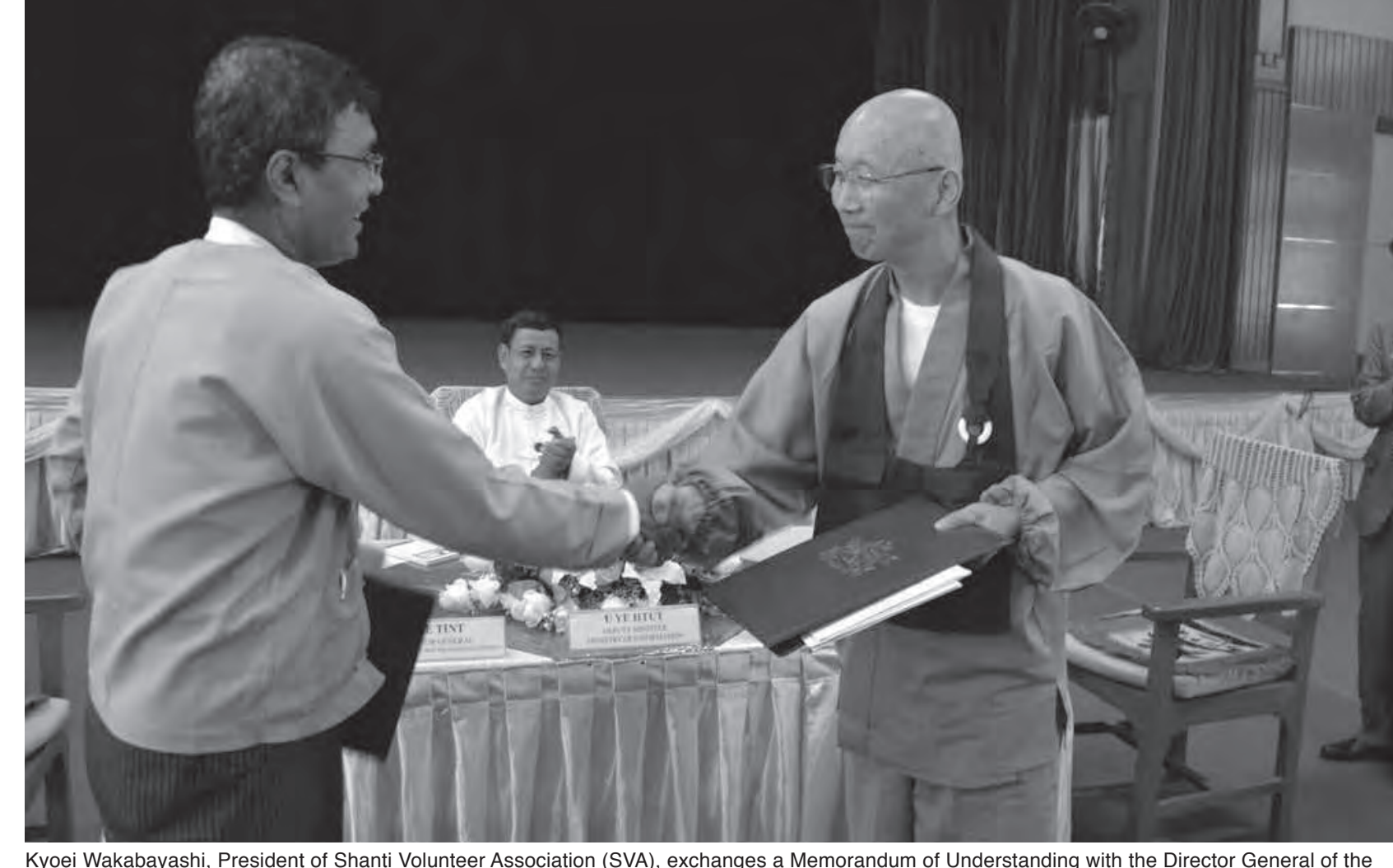

Kyoei Wakabayashi, President of Shanti Volunteer Association (SVA), exchanges a Memorandum of Understanding with
Department of Intormation and Public Relations of Myanmar (lett) in a signing ceremony held in the capital of Myanmar.

\section{We Will Convey Your Warm Hearts to Children}

I would like to extend my heartfelt gratitude to all of you who are supporting SVA's activities. Thanks to your support, I am pleased to present to you our annual report for 2013 and activity plan for 2014 .

Since the SVA started its activities, it has aimed to provide educational support that is rooted in cultures of the target countries and communities. This is because our culture is a condensation of the wisdom of our ancestors, the principles by which we live, and our pride.

We are working to cultivate human resources in each country or region from the viewpoint of valuing their own cultures. We are sowing the seeds so that local staff can become independent and sustain the activities that are rooted in the cultures of each region over long periods of time. Aiming toward this direction, we plan to achieve the independence of the Sikkha Asia Foundation, a local subsidiary of the SVA in Thailand at the end of 2014. Toether with these efforts, the SVA phos end of 2014. Toger han to ope who go to ight en who go to ight elion, in schools and the public local offices and launched projects for supporting chil-

\section{dren who are in difficult conditions.}

Last year, 2013, was the final year of the Three-Year Project Plan for 2011 to 2013 and a milestone year in which we reviewed the achievements and issues based on the three priority goals of the plan

IExpand and enhance our activities to promote read ing books

2 Promote independent operation of our oversea offices B Approach younger generations

For the third priority goal, "Approach younger generations, we feel the need to continue working on it as major goal. Even though it is said that the youth today tend to be inward-looking, we would like to build society through inspiring empathy, where we can "Live Together and Learn Together" based on mutual support. As for other priories, we will incorporate them into our Five-Year Project Plan 2014-2018 to enhance our activities and make progress step by step.

Based on the basic principle of "Live Together and Learn Together," which the SVA has pursued for 33 years, we would like to convey your warm hearts to

Kyoei Wakabayashi, President, Shanti Volunteer Association

\section{The history of SVA}

Volunteers of the JSRC established the Sotosh

1984

The first development project of the SVA was
launched in the village of Baan Wawai, Surin
Province, Thailand.

1985

The SVA commenced its printing project at Ban
Vinai Refuge Camp in Thailand. The SVA also launched library activities at Chian Khan Distric
in Loei Province and the Suanphlu slums in Bang:

1989

The SVA opened a vocational training center
the Kong Toey slums in Bangkok, Thailand.

1991

The Cambodian Office was established in Phnom 列

1992

An office was opened in Vientiane, Laos. The
name of the organization was changed to the "So-"
toshu International Volunteer Association (SVA)."

1995

The SVA undertook relief activities for the victims
of the Great Hanshin-Awaji Earthquake.

1999

The association was renamed the "Shanti Vol-
unteer Association (SVA)." The SVA initiated its
"Campaign to Deliver Picture Books."

2000

The Head Office was opened in Myanmar (Burma)
for refugees. The Rev. Jitsuyo Arima, the torme
executive director of the SVA, passed away.

2001

The SVA began activities to support Afghanistan
refugees after $9 / 11$ in the United States.

2003

The Afthanistan Office was opened. "Serenity on
Earth" by the late Rev. Jitsuyo Arima was pub-
lished.

2005

The SVA participated in "Global Village" of World
Expo 2055 in Aichi Prefecture. The "Supporters for
Asian Libraries" initititive was inititiated.

2011

Offices were established in Kesennuma City
Miyagi Prefecture, and Tono City, Iwate Prefecec

Earthquake. The SVA celebrated its 30 th annive

sary. "Libraries Beyond Borders the trajectory
what an NGO has achieved over the past three

decades in the
was published

2012

The Yamamoto Office was established in Mivag
Prefecture. The SVA started a support project for Yamamoto Town, Miyagi Prefecture and

2013

The SVA concluded a Memorandum of Under-
standing with the Ministry of Information of Myan-
mar.

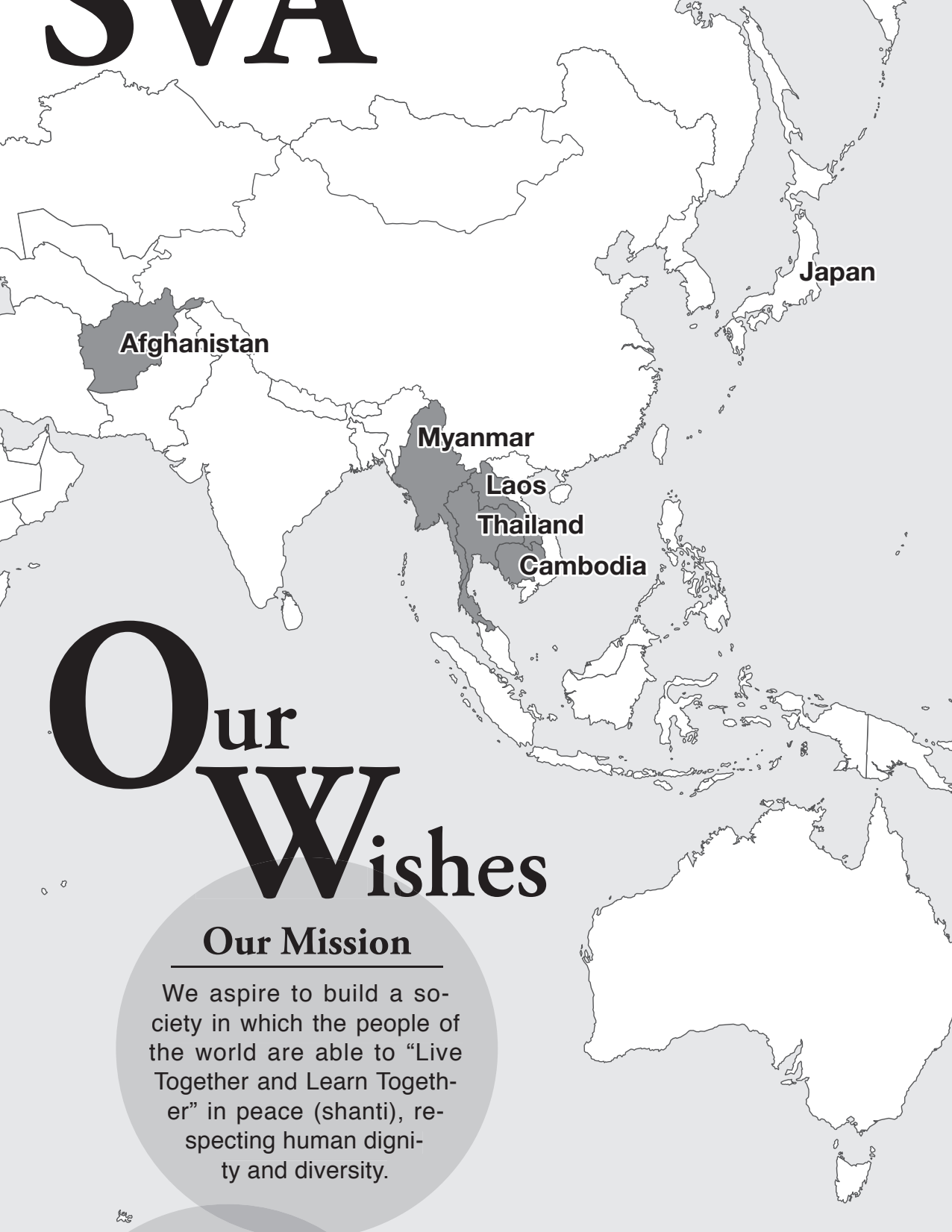

Our Vision

We seek to become an NGO that works alongside individuals, and empowers them to think critically and tions for both personal and societal issues/ problems.

\section{Our Values}

(1) To share the pain, sorrow fering and walk together with them. 2 To value the traditional cultures of each region and respect the differences bedialects. 3To focus on

people to be alopment that will inspire wards self-support. ing mutual support and enhancement among people. 
5

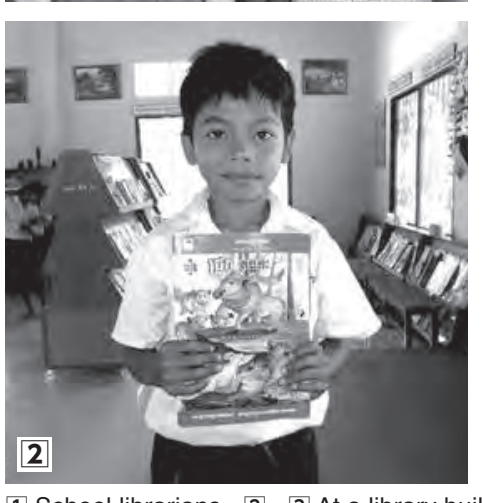

. .

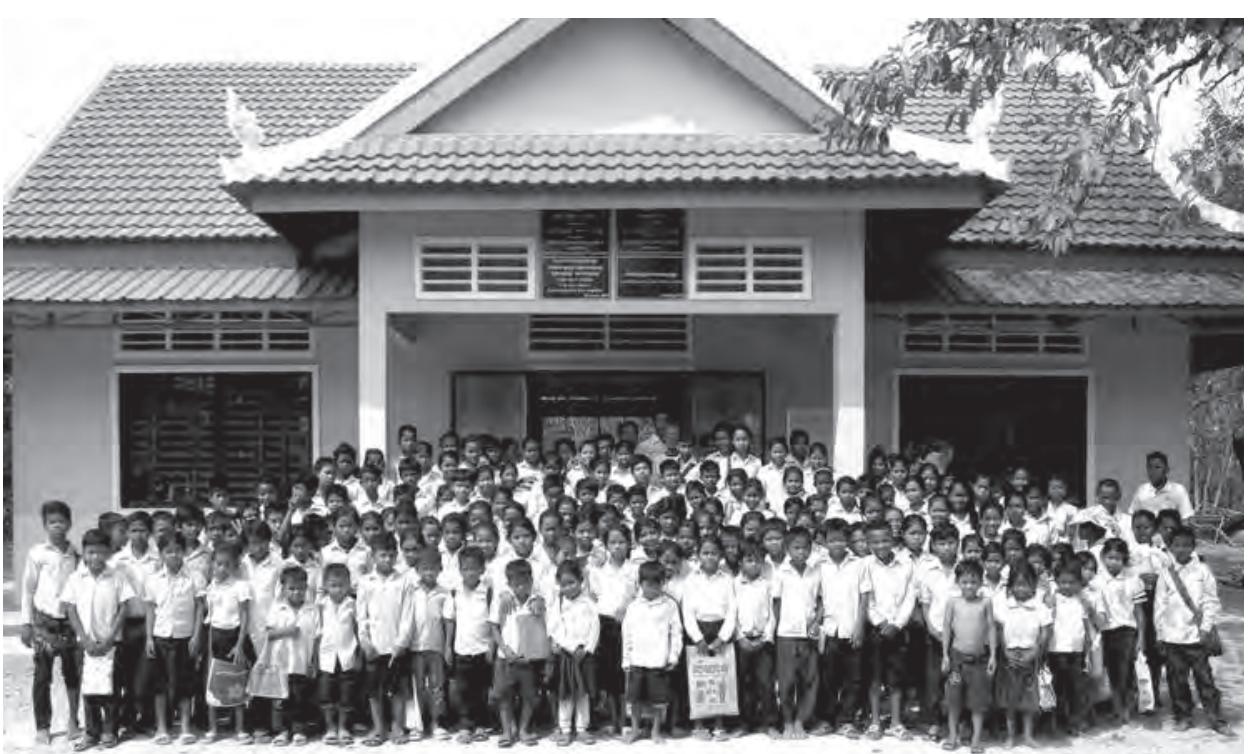

3

The first year of SVA's Three Year Project Plan 2011 2013, which sets out the "Mid-Term Goals," began with efforts to support the survivors of the Great East Japan Earthquake, which brought great sorrow to Japan. After offering relief activities during the emergency period, the SVA worked with people in the disaster-stricken areas create a framework for building places and new communities where people can feel at peace through reading books. We will continue our relief activities so that people can support each other through interpersonal ties and move on towards the future.

With regards to overseas activities, the SVA relocated its activity hubs in Afghanistan, Cambodia and Laos in order to reach out to children and adults who are in difficul conditions with less opportunities. The SVA also planned

new projects in Myanmar, a country where it will be launching new activities. In these three years, the SVA changed the direction of its activities significantly.

The SVA temporarily suspended most of its overseas efforts for the Great East Japan Earthquake victims. We reorganized our stucture and resumed overseas relief programs in fiscal 2013. By November 2013, we responded to six cases of damage caused by windstorms or llooding that occurred in Japan and overseas. In December 2013, we started supporting the victims of Typhoon Haiyan that hit the central Philippines.

Our four priority goals and the achievements in the last three years were as follows:

\section{Review of 2011-2013}

Aim to Expand Reading Promotion Activities The SVA provided reading promotion activities fo 2,559,918 children through libraries, mobile libraries an publication of picture books. This exceeded our target of 1.65 million children.

- Aim to Promote Autonomous Operation at Overseas Offices

The SVA promoted the "Five-Year Plan for Autonomous Operation" of the Sikkha Asia Foundation, which is our local subsidiary in Thailand, and started transferring the conventional SVA supporters to the Foundation in fiscal 2013. In all countries where the SVA runs activities except Thailand, we formulated a "Three-Year Plan for Autonomous Operation" for our overseas office an stepped up efforts to cultivate national SVA staff and strengthen organizational capability.
- Aim to Expand Our Projects in New Countries The SVA conducted a research on planning new projects in Myanmar in February 2013. It was registered as a non-governmental organization by the Ministry of Home Affairs of Myanmar in November 2013. The SVA concluded a Memorandum of Understanding (MOU) with the Myanmar Ministry of Information as a cooperative partner.

- Aim to Build Relationships with Supporters in a Wide Range of Generations

A total of 8,168 people joined our activities as new super generations, in their 30 s or younger, accounted for
$15.4 \%$ of the total number of the supporters. porters, exceeding our target of 8,000 people. Young-

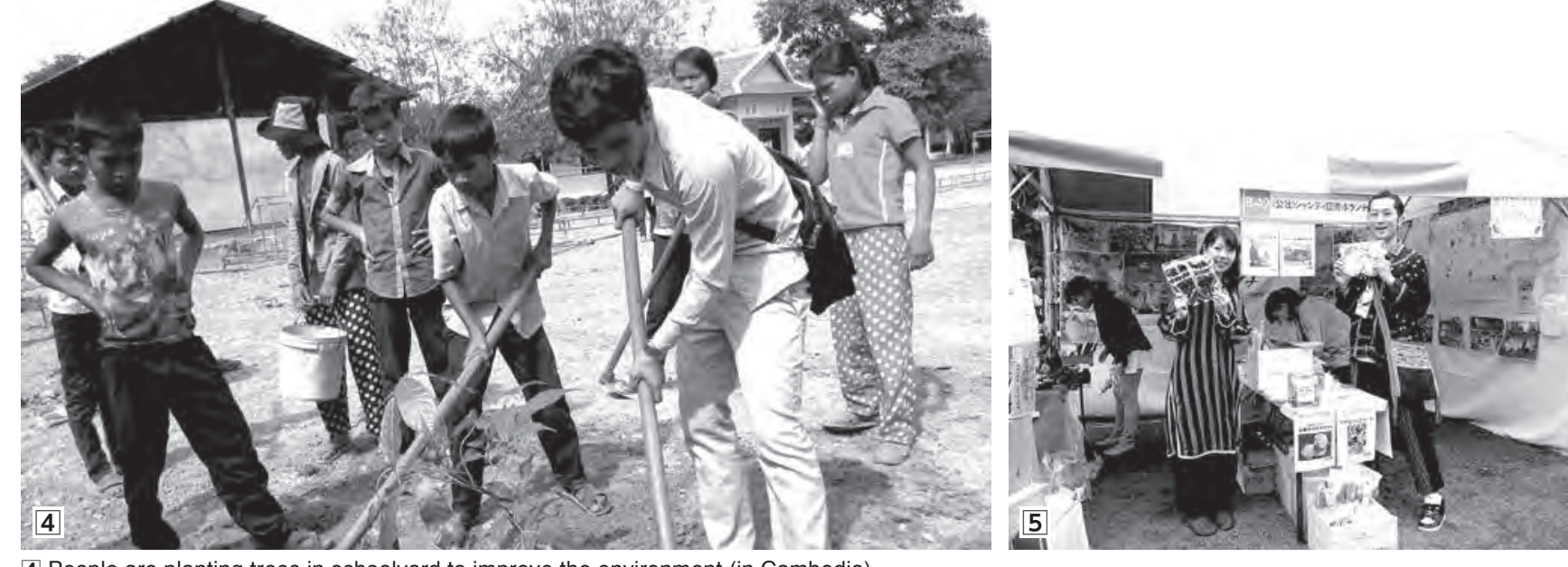

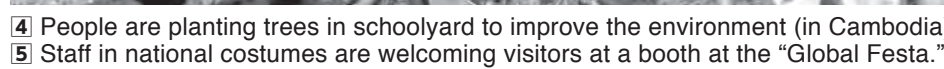

\section{Towards 2014}

The economies in Cambodia and Laos have been growing at roughly 6 to $8 \%$ per year, as the establishment of the ASEAN Economic Community approaches in 2015 On the other hand, some point out that a widening gap between the rich and the poor is hampering the trend of democratization and leading to an unstable political situation. These counties are remaining in a vicious cycle, where the poverty-stricken people are forced to live in harder conditions because of frequent disasters caused by worsening climate changes

As we approach the 2015 target date for the Millennium Development Goals (MDGs), further efforts are being made to achieve the goals. At the same time, there is an increased discussion to develop a post-2015 development framework, and Realization of Universal Human Rights and Human Security" is being examined once again as a principal goal of the framework. We feel that this is in line with the SVA's mission, "We aspire to build a society in which the people of the world are able to live together and learn together in peace (shanti), respecting human dignity and diversity."

In 2014, the SVA will start the Five-Year Mid-Term Action Plan 2014-2018, which focuses on promoting reading and library activities. We set the following two main midterm goals:

To promote reading and library activities, so that even those in difficult conditions or disadvantaged situations can cultivate their ability to think and solve problems on their own.

To advocate the mainstreaming of reading promotion and library activities in the education policies of national and regional governments, as well as related institutions.

We will deal with the following four priorities in 2014, the first year of the Five-Year Mid-Term Action Plan:

Reorganizing Program Development and Operation

The SVA will launch projects such as public libraries, non-formal education and publication of children's books in Myanmar.
We will implement the projects using our local offices as hubs, in order to conduct activities for people in Cambodia and Laos who are difficult to reach.

We will start reorganizing our policies and projects so that our activities for promoting reading can be incorporated in all our projects.

We will strengthen networks with partner organizations in order to actively conduct emergency humanitarian aid in Japan and overseas.

We will perform an interim assessment of our support for econstruction for the Great East Japan Earthquake and

Improving Public Relations and Finance We will strive to have 2,000 more supporters who will assist us, mainly in our projects such as the Asian Library Supporter, Campaign for Delivering Picture Books, Donating Books Project, Craft Aid and Fundraising for Children in Asia.

$\checkmark$ Enhancing Organizational Management and Administration

The Sikkha Asia Foundation (Thailand) will be established as an independent, self-supporting entity by the end of fiscal 2014

SVA Directors in charge will organize working groups to discuss basic strategies regarding the following:

Overseas projects

The concept and future direction of the project for eastern Japan

3 Fund-raising and marketing

We will conduct an external audit once every thre months to strengthen the account checking system.

- Human Resources Development

The SVA will formulate a "Fundamental Policy for Huma Resources Development," which outlines the desired qualities of Japanese and local staff, and develop a "Hu-
man Resource Development Plan." develop an activity plan up to the end of 2015. 


\section{Myanmar}

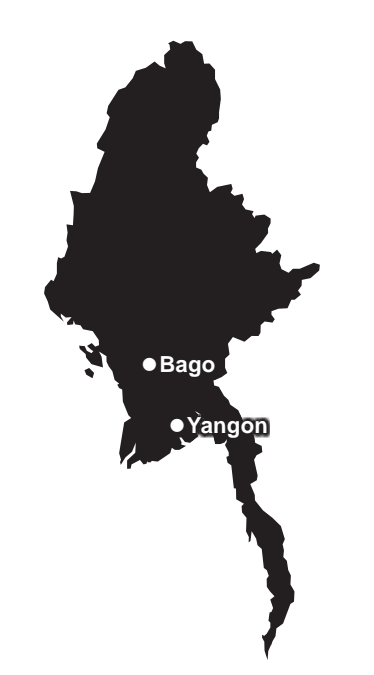

- Official language : Burmese - Capital : Naypyidaw - Population : 63.67 million (IMF data as of 2012)
- Per capita GDP : US $\$ 834$ (IMF data as of 2012) - Currency : Kyat (K)
- Time difference with Japan 2 and half hours

An influx of foreign capital has A een continuing since 2013
with the rapid democratization after a civilian government was
established in 2011. The number of Japanese companies increased rapidly from 53 in 2011
to 133 in 2013. The Japanese announced that it would gran
$¥ 91$ billion to Myanmar while waiving the $¥ 500$ billion overliteracy rate of adults is esti-
mated to be around $55 \%$, much lower than the number made dren who can graduate from elementary school remain low at $56 \%$. There remains an issue of the weak people who
are left behind despite the ad are left behind des
ministrative reform.

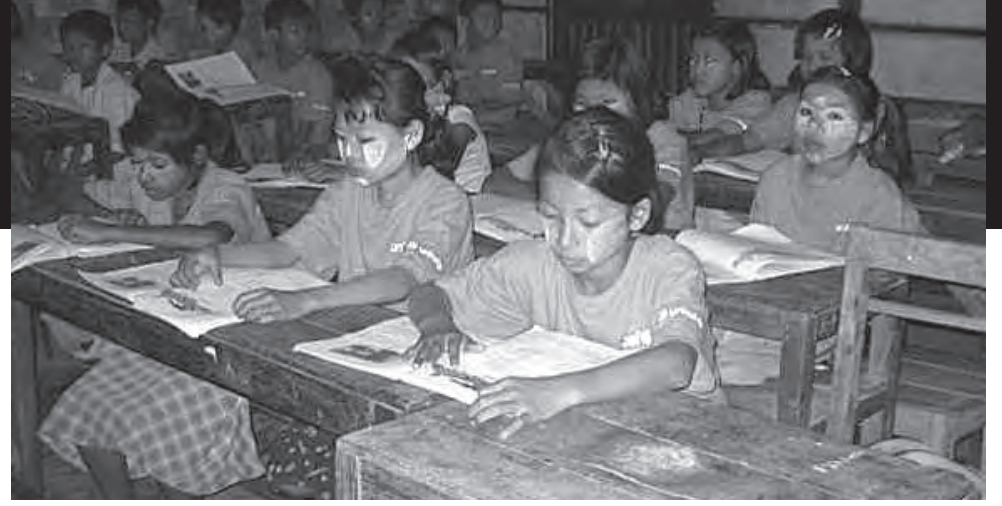

In 2013, we conducted research for launching new support projects in Myanmar and prepared for opening
new offices. In November, the SVA signed an MOU (Memorandum of Understanding) with the Ministry of Inormation of Myanmar. It has been 10 years since the SVA last opened an office and operated projects for suprecipient country.

In 2014 we are planning to set up offices in Yangon and Pyay Distric kilometers northwest of Yangon. Four support projects will start mainly in Bago Region

In Myanmar, there are more than 1,500 temple schools which are buit These schels are similar to the old Japanese "Terakoya." The study curriculum of temple schools is the same as that of public elementary schools. Many children from poor families go emple schools because they can at-

end the classes entirely gratis. There are some problems with the quality of educalion, such as dilapidated schoo schools are operated beause templo the temples and the communities. The SVA will carry out projects to reform the temple schools.

Also, the percentage of children who are able to graduate from elementary school is only $56 \%$, although enrolcan't go to school due to povery, to support "Life Skill Education Program" that teaches children what they need to live, private "night elementary schools" where they can get an elementary school diploma, and "Comthere are not many quality books for children in Myanmar and most librarians are not experienced. Thus the ing public libraries and for supporting publishing of children's books.

\section{Plan for 2014}

Project for Reforming

"Terakoya Temple schoo

- Construct two temple schoo
buildings and one orphanage at tached to the school.

-Distribute 200 children's books to 14 temple schools and provide seminars for teachers.

Project for Supporting

Who Can't Go to School

- Support seminars of lecturers and administration of the "Life Skill Education Program,

is run by a local NGO.

- Support administration and hold seminars for teachers of night

- Donate teaching materials, books Learning Centers. Train lecturers and plan and implement programs.

Public Library - Durmese and furniture and to 14 public libraries. Hold a seminar on children services for librarians.

- Carry out mobile library activities using motorcycles and cars. Donate personal computers libraries for Internet access.

Project for Publishing

\section{Picture Books}

and Children's Books

- Hold a picture book contest in cooperation with an associatio Burmese writers. of picture books or children's books and publish and distribute

them. and children's books.

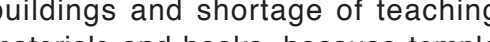
the SVA will work with local NGO SVA will carry out projects for improv-

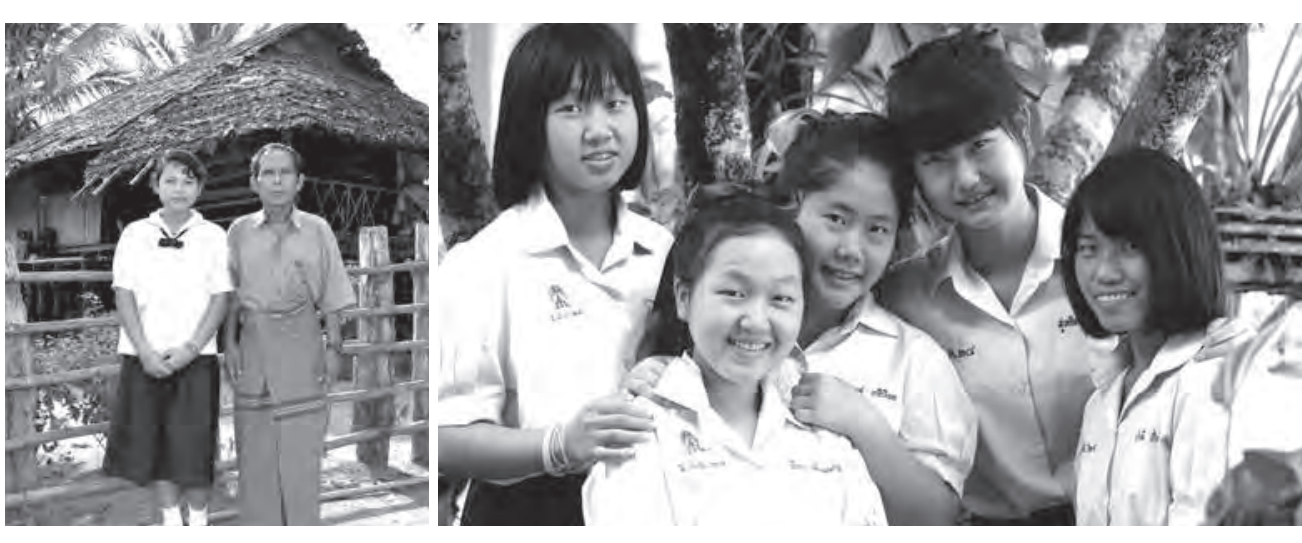

In Thailand, although free education system started in 2009, parents are of lack of operating funds. There are many necessities that must be prepared for school life such as school uniforms and tools, and the cost of attending school is also placing a large financial burden on poor families many cas

In 2014, the SVA plans to work on a scholarship project in the areas of the Sikkha Asia Foundation (SAF) autonomous organization has entered its fifth and final year, and the SVA will focus its efforts on establishing relations with supporters in Japan and im proving the fundraising capacity bot

2013 Activity report

\section{Scholarships}

Improvement Project Donate 200 children's books
The SVA provided scholarships for a lotal of 399 students, including 375 and 24 university students, for students of ethnic minorities in Phayao and Tak Provinces and in the slum districts of Bangkok. Breakdown of the high school scholarship students were

ed interviews with teachers as well. Scholarship award ceremony for the first half-year is held in May, and cerein November every year. The SVA holds a year-end evaluation meeting the year.

On November 1, 2013, Tha the amnesty bill that could have led to the return from exile of tormer Prime Minister Thaksin large-scale demonstrations in
Bangkok. The lower house was Bangkok. The lower house was
dissolved by Prime Minister $\mathrm{k}$ place in February. How ever, because of the boycotts of the election and demonstrawhich prevented people from going to polling stations, the
constitutional court declared the election invalid. Confused
situation is expected to extend over a long period. Regional gap between urban significant. For exampl stin areas near the border with Myanmar, school children in
lower grades go to branch schools, which have only smal branch school, those children city while living in a dormitory in many cases. - Organize a scholarship studen (45 rom Phayao Provnce, 200 from

The SVA carried out home visits for the secondary selection of new scholarship students. We visited 72 Province and 19 in the slum district of Bangkok.

In Tak Province, the SVA strengthened cooperation with school

Every year in October, 60 representatives of scholarship students gather learn about volunter spirits and expe rience volunteer activities. The camp also provides an opportunity for the students to learn about the differences in cultures and life styles, through traditional dances, songs and musica instruments.

\section{Plan for 2014}

\section{Scholarships}

- Provide scholarships for a total o 400 students, including 375 junior and 25 university students, for the Mon people in Phayao Province, and students in the Tak Province, Bangkok. Increase the amount of scholarships for junior and senio high school students to be able to concentrate on study. Hold schoarship award ceremonies twice a gional culture.

- Make home visits once a year. from all regions. 


\section{Japan}

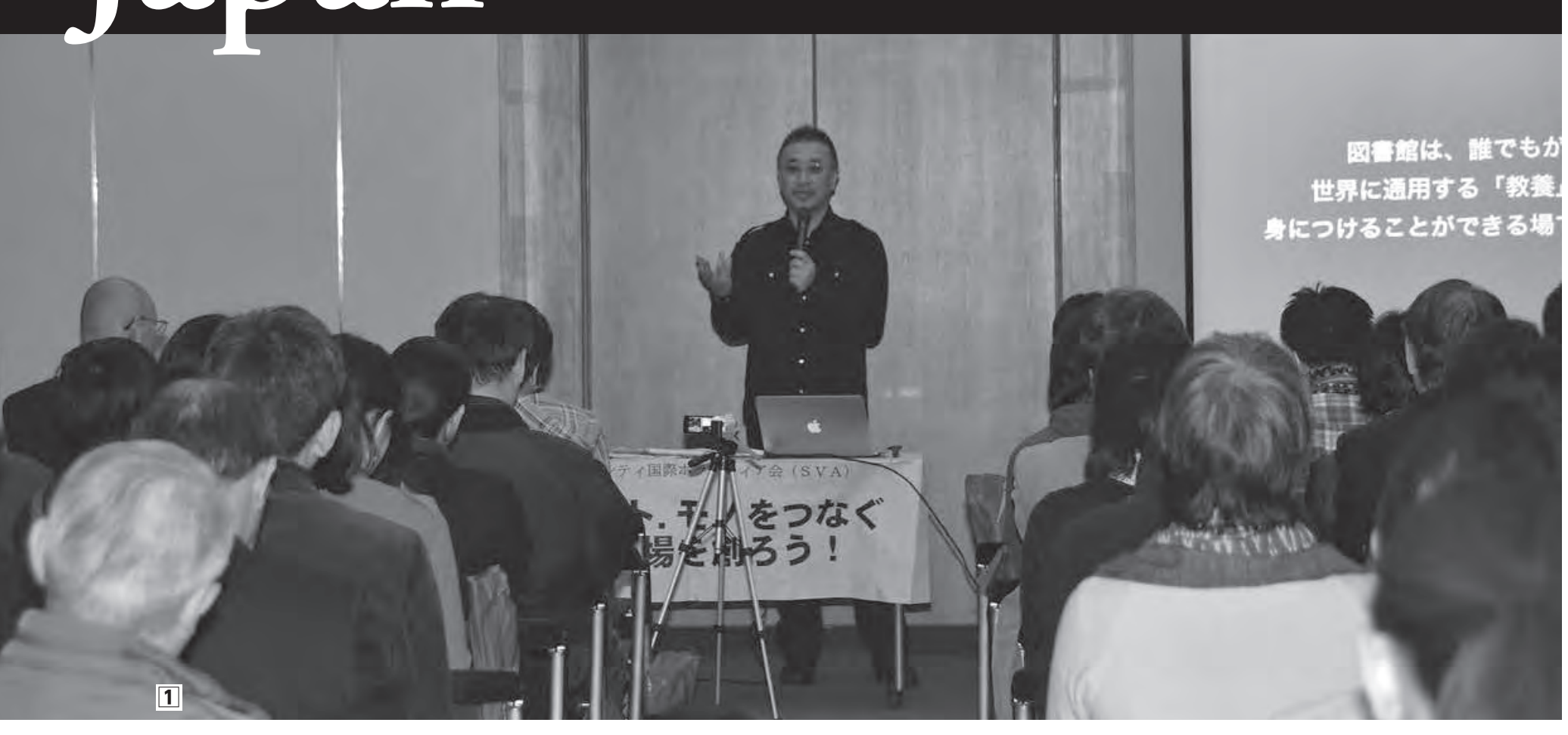

We would like to express our gratitude for your warm support of our activities in 2013.

Many of those who already knew about Shanti have become supporters who will continually support us. Additionally, we have welcomed about the current status and challenges of our activities abroad and in Japan, while placing a high priority on our relationship with people.

(1) Yuichiro Hanai, founding director of "machi tosho terrasow", the Obuse Town Library in 2 Participants of the study tour with children in a refugee camp.

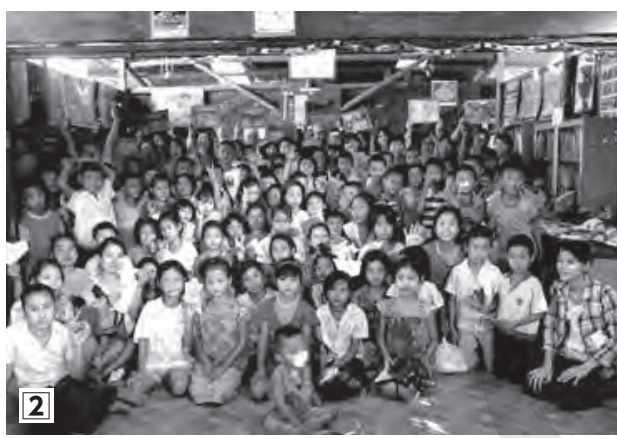

\section{Asian Library Supporter}

Network of supporters expanding

We welcomed 338 new Asian Library supporters this year and the number of supporters totaled 979 by the end of 2013. The network of supporters has been expanding. Some supporters volunteered their time for a study
hoku!"

In the spring, we sent our supporters photo greeting cards with messages written by children. We will keep supporters and the children in Asia.

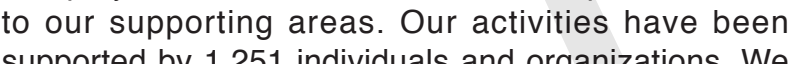
continued to receive a grant from Bellmark Educational Support Foundation and transportation support from plan to call for cooperation with a goal of delivering 15,000 books to children.

\section{Craft Aid}

Conducted a field survey of manufacturers We conducted a written survey of our 16 partner manufacturers in Thailand, Cambodia, Laos and Afghanistan in fiscal 2013. In Laos and Thailand, we conducted field surveys and directly interviewed the craft workers.

We will strive to create new products by listening to the voices of craft workers and sales supporters.

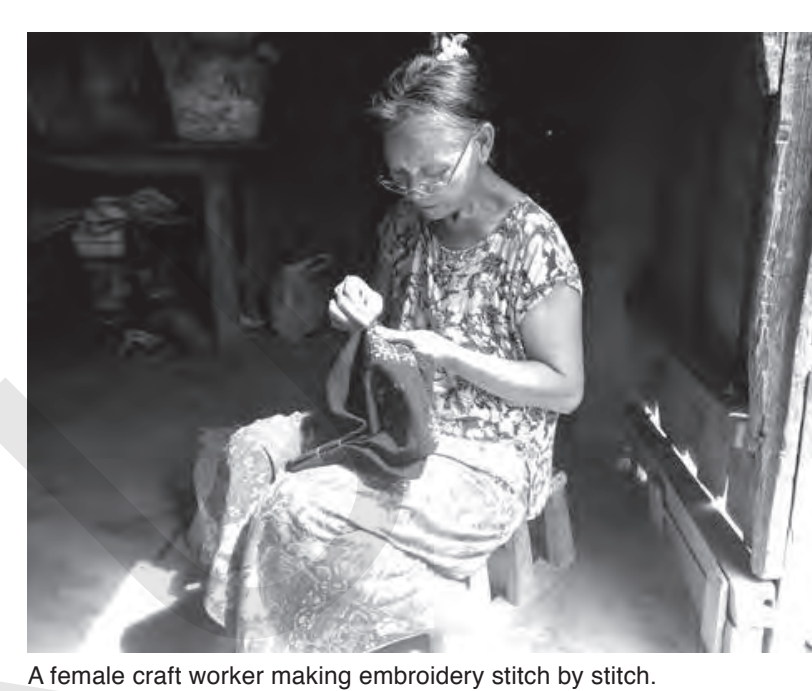

\section{Public Relations}

Providing an opportunity

to exchange opinion with supporters

In 2013, we held 19 debriefing sessions by staff members working at overseas offices and 475 people participated. Additionally, we had three debriefing meetings on the support activity for the Great East Japan Earthquake victims. We also organized exhibition and lecture meetings at libraries, such as Kitashinjuku Library and Yotsuya Library, both in Shinjuku Ward Prefectural Library, and Shimane Prefectural Library We encouraged local members and supporters of Asian libraries to attend these events, aiming to create opportunities to meet and exchange views face-toface locally.

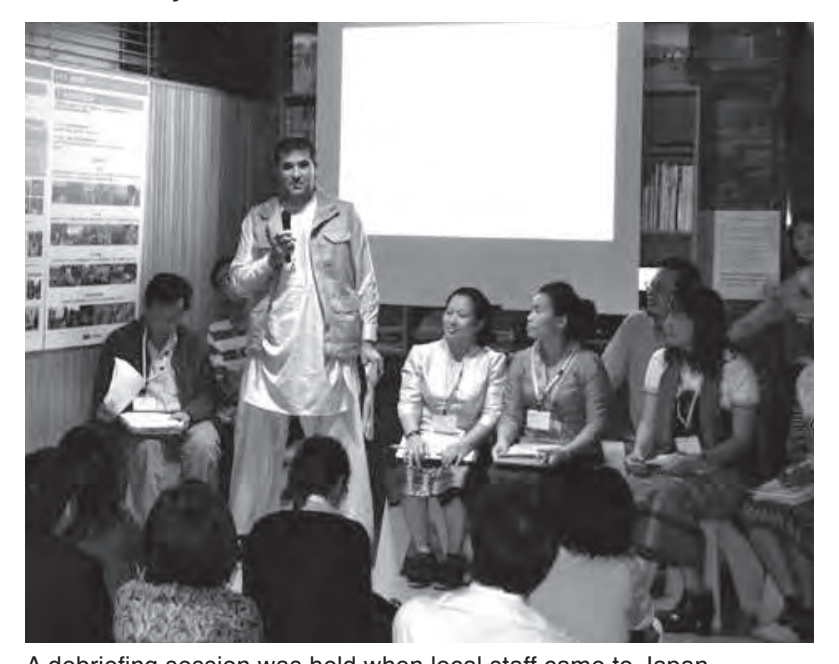

Recycle Book Aid

Supporting Asian children with used books, etc. In 2013 we started a new approach by creating an envelope-type flyer to ask for donation of at least one book and such, and many people cooperated with us. In 2013, we received 1,057 applications, including 288 new applications, and received 146,000 books, CDs and DVDs in total.

In 2014, the project will be renamed the "Book Donation Project:

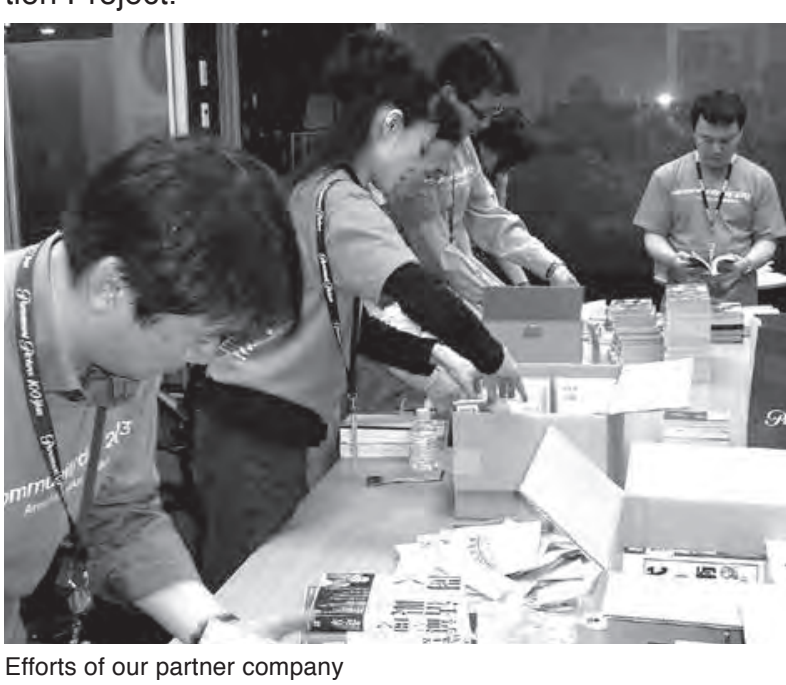

Support for Overseas Projects

\section{To support overseas projects}

Thanks to the support of many people, the SVA is close to achieving its goal for 2013 regarding the donations designated for overseas projects. In Laos we supported the planning of new projects. In Afghanistan we conducted the terminal evaluation of the project, and supported the formulation of action plan for au(t) erched

In 2014, we will continue to focus on fund raising, human resource development, and supporting project management.

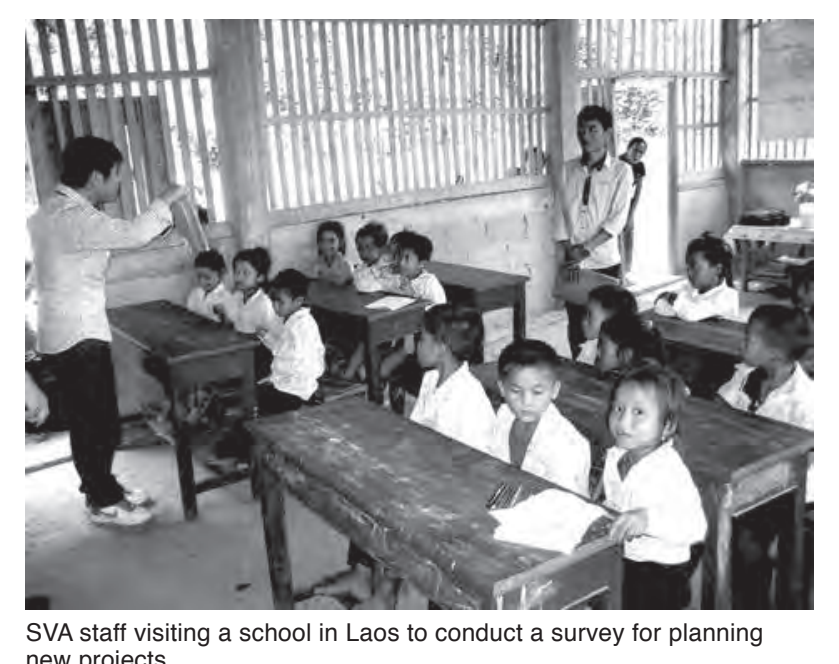

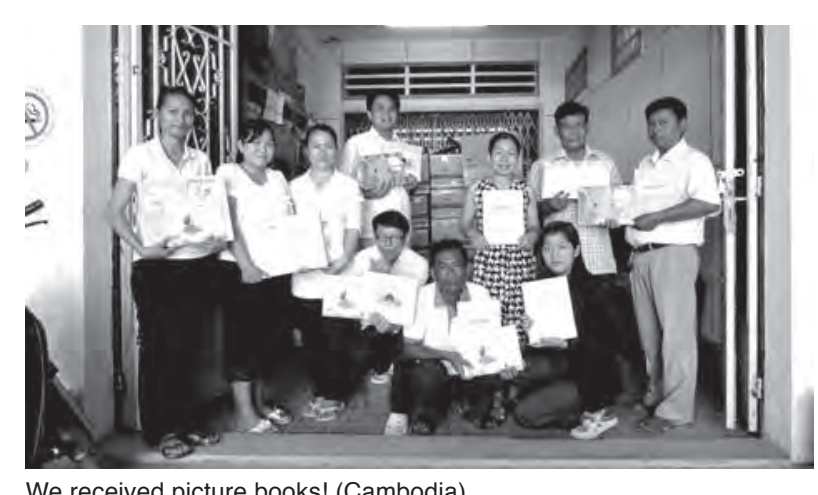




\section{Financial Report}

\begin{tabular}{l|r}
\hline \multicolumn{1}{c|}{ Income } & \multicolumn{1}{c}{ Year 2013 } \\
\hline Bank Interest & 279,057 \\
\hline Membership Fee & $27,033,000$ \\
\hline Donation & $423,869,622$ \\
\hline Subsidy & $214,921,703$ \\
\hline Programs for Profit & $51,956,687$ \\
\hline Others & $6,146,661$ \\
\hline Total & $\mathbf{7 2 4 , 2 0 6 , 7 3 0}$ \\
\hline
\end{tabular}

\begin{tabular}{l|r}
\hline \multicolumn{1}{c|}{ Expenditures } & \multicolumn{1}{c}{ Year 2013 } \\
\hline Public Interest Purpose 1 & $16,929,138$ \\
\hline Thailand & $138,349,392$ \\
\hline Cambodia & $41,496,223$ \\
\hline Laos & $52,320,969$ \\
\hline Myanmar (Burma) Refugee & $142,225,834$ \\
\hline Afghanistan & $3,019,717$ \\
\hline Myanmar & $37,989,669$ \\
\hline Others & \\
\hline Public Interest Purpose 2 & $127,488,942$ \\
\hline The Great East Japan Earthquake & $14,028,648$ \\
\hline Emergency Relief(Overseas) & $3,746,295$ \\
\hline Others & \\
\hline Public Interest Purpose 3 & $67,440,276$ \\
\hline Public Interest Purpose (Common) & $\mathbf{6 5 9 , 6 6 2 , 1 8 7}$ \\
\hline Total: Public Interest Purpose & $\mathbf{4 0 , 7 9 9 , 3 5 1}$ \\
\hline Profit-making Purpose & $\mathbf{3 5 , 0 7 6 , 8 9 2}$ \\
\hline Administration & $\mathbf{7 3 5 , 5 3 8 , 4 3 0}$ \\
\hline Grand Total &
\end{tabular}

\section{SVA Association members}

Total number of members : 1,932 persons

Staff member : 313 persons

Individual : 259 persons

Organization : 54 organizations

Supporting member : 1,619 persons

Individual : 1,431 persons

Organization : 188 organizations

(as at December 31, 2013)

Honorary President : Rev. Zendo Matsunaga

\section{Advisor :}

Mr. Fusao Adachi

Rev. Hojun Abe

Prof. Yutaka Aramaki

Mr. Masahiro Onoda

Technical Adviser :

Ms. Ryoko Sato

Mr. Yoshifumi Tajiri

Rev. Eisho Kawahara

Mr. Takashi Shiraishi

Rev. Sojun Matsuno

Ms. Yayoi Tanaka

Ms. Sumiyo Matsuo

\title{
SVA Executive Board members
}

President : Rev. Kyoei Wakabayashi

Vice President :

Rev. Gido Sambe Ms. Kayoko Kozu

Chief Executive Director : Rev. Shunko Chino

Managing Director:

Ms. Hitoshi Ichikawa

Prof. Tatsuya Hata

Rev. Bunmei Hayasaka

Board of Directors :

Rev. Shiro Arima

Ms. Yasuko Isobe

Mr. Makoto Okamoto

Rev. Rigyo Kurashina

Rev. Hitoshi Jin

Mr. Hisashi Seki

Mr. Yohji Nagahama

Ms. Hitomi Nagahori

Mr. Shuichi Nomura

Rev. Kenshi Fueoka

Mr. Katsumasa Yagisawa

Mr. Keiji Watanabe

Ms. Chieko Watanabe

Auditor :

Mr. Toshiyuki Aoki

Mr. Kazuo Masuda

\section{Shanti Volunteer Association}

\author{
Jibokaikan 2,3F, Daikyo-cho, Shinjuku-ku, Tokyo \\ Phone +81-3-5360-1233 FAX +81-3-5360-1220 \\ Email info@sva.or.jp Official Website http://sva.or.jp/english/about/
}

Published by Shanti Volunteer Association

Translated by International Language Volunteers of the Tokyo YWCA

All rights reserved,October 2014 